\title{
Implementation of Experiential Learning in Pathology: Impact of HIPON Project Concept and Attainment
}

Presented at 1st International Online BioMedical Conference

REVIEW

Andreas C. Lazaris ${ }^{1}$, Olga Riccioni ${ }^{1,2}$, Maria Solomou ${ }^{3}$, Ilias Nikolakopoulos ${ }^{1}$, Evangelia Vemmou ${ }^{1}$, Stefanos Karamaroudis ${ }^{1}$, Maria-Evanthia Sotirianakou ${ }^{1}$, Charalambos Vrasidas ${ }^{3}$, Goce Armenski ${ }^{4}$, Sven Seiwerth ${ }^{5}$, J. Han J.M. Van Krieken ${ }^{6}$, Efstratios S. Patsouris ${ }^{1}$

\section{Abstract}

Background: In pathology training, one of the current, hardest and most important tasks is the conversion of the extensive amount of available data into medical experience. This challenge is linked with an innovative project entitled "ICT emodules on HistoPathology: a valuable online tool for students, researchers and professionalsHIPON".

Aim \& Objectives: The project has resulted in a multi-language elearning platform which aims to imprint professional experience in a way that medical students, researchers and professionals can develop their own necessary practical dexterities in the huge field of modern Pathology.

Methods: The basic concept underling HIPON's methodology is the introduction of experiential learning based on real cases.Experiential learning is a process through which students develop knowledge, skills, and values from direct experiences; the key element is the student, and knowledge is gained as a result of being personally involved in the pedagogical approach.

Results: By implementing experiential learning, there is a move to a more student-centered view of learning. The educator's most important responsibility becomes to search out and construct meaningful educational experiences that allow students to solve real-world problems; the result is that any abstract, inert knowledge that students used to memorize from dusty textbooks comes alive as they participate in the practical application of knowledge.
1 First Department of Pathology, Faculty of Medicine, The National and Kapodistrian University of Athens, Athens, Greece.

2 Faculty of Medicine, La Sapienza University of Rome, Rome, Italy.

3 Center for the Advancement of Research \& Development in Educational Technology (CARDET), Nicosia, Cyprus.

4 Faculty of Computer Science and Engineering, "Ss. Cyril and Methodius" University, Skopje, FYROM.

5 Institute of Pathology, University of Zagreb School of Medicine, Zagreb, Croatia.

6 Department of Pathology, Radboud University Nijmegen Medical Center, Nijmegen, The Netherlands.

\section{Contact information:}

Andreas C. Lazaris.

” alazaris@med.uoa.gr 
Conclusion: HIPON provides an innovative platform which introduces medical experience in diagnostic practical issues of Pathology. Experiential learning offers rich opportunities for learning for participants and teachers/facilitators. Choosing powerful activities that increase learner involvement, following the experiential learning cycle in reflecting, generalizing and applying learning, giving and receiving valuable feedback in the moment, greatly increase learning retention and the quality of learning.

\section{Keywords}

Experiential Learning;

Pathology; Education Platform; HIPON

\section{Background}

"ICT e-modules on HistoPathology: a valuable online tool for students, researchers and professionalsHIPON" is a project supported and co-funded by the Lifelong Learning Program of the Education, Audiovisual and Culture Executive Agency, The Commission of the European Union (project reference number: 531203-LLP-1-2012-1-GR-KA3KA3MP, Grant Agreement: 2012-4909/001-001, Key Activity 3-ICT Multilateral Projects), and coordinated by Associate Professor Dr Andreas C. Lazaris from Medical Faculty of the National and Kapodistrian University of Athens, with the following partners: University of Zagreb School of Medicine, Croatia, Radboud University Nijmegen Medical Centre, the Netherlands, Centre for the Advancement of Research \& Development in Educational Technology (CARDET), Cyprus, and Faculty of Computer Science and Engineering, Ss. Cyril and Methodius University, Skopje, FYROM.

The whole project aspires to be recognized as of high pedagogic value, creating an online environment that speeds up the ability to learn and achieves to transfer, step by step, the way of expert diagnostic thought in Pathology to its users so that the latter increase their professional experience and not just be provided with plain information of encyclopedic type. Our motivation is to promote trustworthy professional experience to HIPON users so that they develop their own necessary practical dexterities in the huge field of modern Pathology, through an interactive educational web-based platform (www.hiponproject.eu) equipped, above all, with interactive case presentations based on successive microscopic images with guiding questions/legends and annotations, as well as with educational presentations of histologic slides in video and digitalized (virtual) slides.

In order that the results of our efforts are promoted, the following HIPON-related journal publications and conference speeches/announcements/ papers have been carried out:

\section{- Full paper publications}

1. A Web-based Attempt to Acquire Professional Experience in Pathology: The HIPON Project. MedEdPublish 2013, www.mededworld.org.

2. HIPON Project: Acquiring Medical Experience through an E-learning Platform. A New Perspective in Pathology Education. New Perspectives in Science Education. Edition 4, 2015.

3. Learning Authentically through HIPON Platform. The Future of Education, 2015.

4. Acquiring experience in pathology predominantly from what you see, not from what you read: the HIPON e-learning platform. Advances in Medical Education and Practice 2015:6, 1-7. 


\section{- Conference invited speeches on HIPON}

1. $25^{\text {th }}$ European Congress of Pathology, Lisbon 2013.

2. $27^{\text {th }}$ European Congress of Pathology, Belgrade 2015.

\section{- Conference participations with abstracts}

1. $25^{\text {th }}$ European Congress of Pathology, Lisbon 2013. Abstract published in Virchows Archiv The European Journal of Pathology, Vol. 463, No 2: page 227.

2. $26^{\text {th }}$ European Congress of Pathology, London 2014. Abstract published in Virchows Archiv The European Journal of Pathology, Vol. 465, Suppl.1: page S286.

3. $38^{\text {th }}$ European Congress of Cytopathology, Geneva, 2014. Abstract published in Journal of Cytopathology, Vol. 25, Suppl.1, 22-78.

4. $30^{\text {th }}$ Congress of the International Academy of Pathology, Bangkok 2014. Selected by the Scientific Committee as one of the 17 out of 400 posters to be orally presented at a special session. Abstract published in Pathology Vol. 46, S2: page S124.

5. $39^{\text {th }}$ European Congress of Cytopathology, Milan, 2015. Abstract to be published in Journal of Cytopathology.

6. $9^{\text {th }}$ International Online Medical Conference, 2015

7. $26^{\text {th }}$ ESC Medical Students' Conference, Berlin, 2015.

In the above multiple presentations, the position of experiential learning in academic education and the application of this type of learning in HIPON e platform were extensively discussed. The impressions we heard were encouraging for all HIPON partners. The following text is linked with the thematic of the conducted discussions.

\section{HIPON Concept}

Conventional medical books follow an encyclopedic-type formula citing single diagnostic features of specific diseases without initiating the reader to think as a professional. No patient is ever going to ask the clinician what the symptoms of a disease are to see if he/she suffers from it. Using his/her experience, the doctor should assess the symptoms and findings from the examination of each patient so as to arrive at the correct diagnosis. Accordingly, in terms of pathology training, the "encyclopedic" knowledge of pathology is of secondary importance by comparison to the "experiential" one. There is indeed a need to record online the diagnostic experience of charismatic pathologists who have focused their professional activity at a specific field of the vast medical specialty of Pathology. Our project seeks to meet this need. In this context, the aim of HIPON is not just to provide its users with another internet medical atlas of images, but to teach medical students and resident doctors in pathology the right way to approach microscopic images of tissues and cells, that is how to recognize the basic patterns of tissue lesions, disregarding possible confusing details, and, without sticking their thinking to a specific diagnosis from the beginning, how to correlate these patterns with the basic underlying mechanism of disease and with relevant clinical and laboratory patient data so as to define an appropriate differential diagnosis and end up to the correct diagnosis, similarly to every-day practice in pathology.

For homogeneity reasons, a prototype-guide for all presented cases has been developed, in which the diagnostic procedure for each case is presented step by step (Figure 1). This prototype is structured in such a way that, in parallel with the step by step image apposition, each user is able to tackle a series of optional questions on the images shown as well as to declare his/her possible requests (clinical data, special stains, molecular markers, etc), similarly to every day practice in Pathology, in order to select the correct diagnosis among several alternatives, which is the final quest. This prototype allows the annexation in the overview section of general original image files -that do not focus on a specific presented case- as links, giving the pos- 
Figure 1: A case of active cranial arteritis as an example of the step by step diagnostic procedure presentation in HIPON "Cardiovascular system" unit.

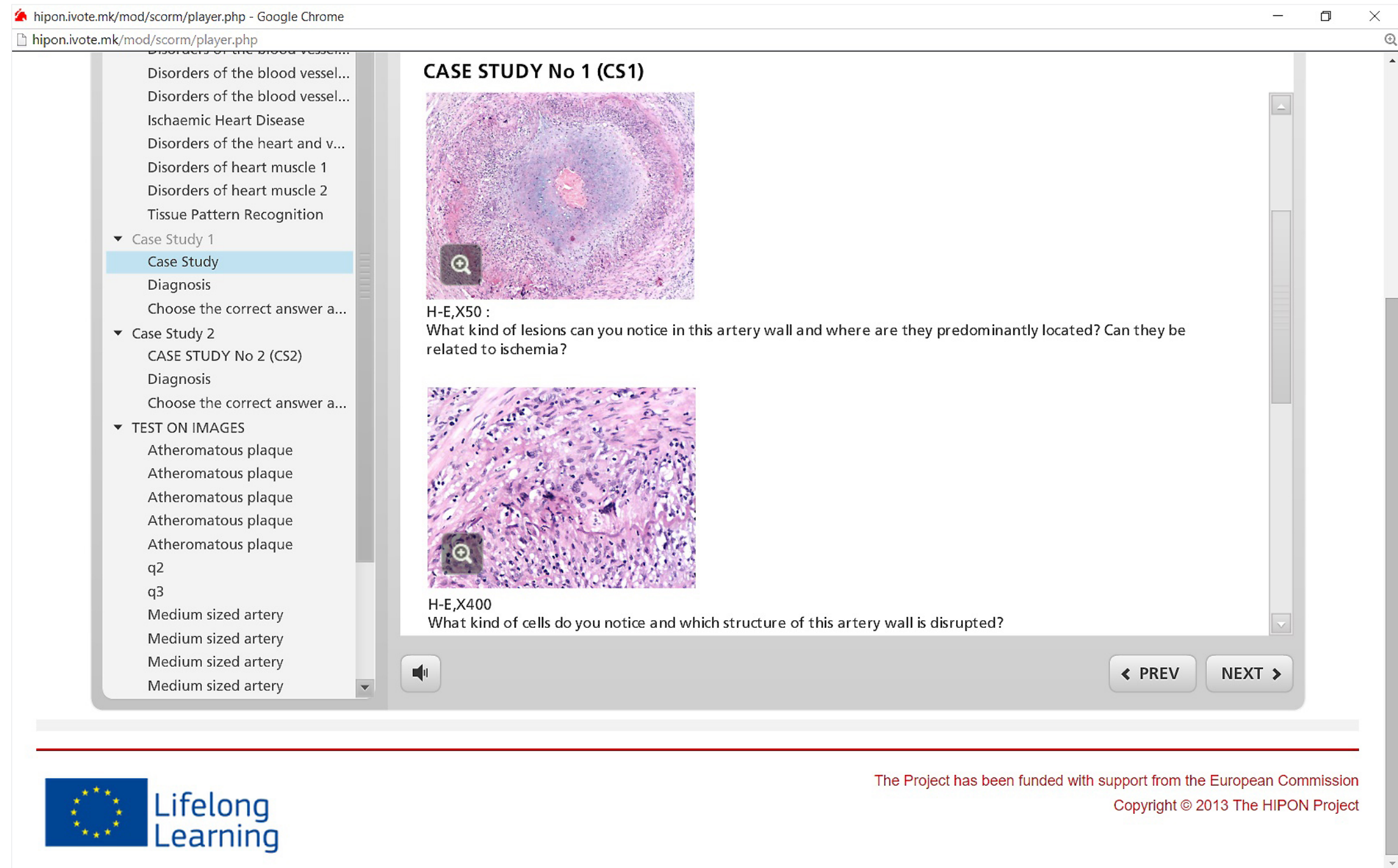


sibility to the user, when he/she is not successful in finding the diagnosis or in answering the proposed image-based questions, to study these general files in parallel with suggested references/weblinks. Furthermore, there is a possibility of scanning at least one characteristic histological slide for each HIPON unit/chapter so that the relevant digitalized slide becomes available to each HIPON user.

\section{Experiential Learning}

Experiential learning is a process through which students develop knowledge, skills, and values from direct experiences outside a traditional academic setting; the key element is the student and knowledge is gained as a result of being personally involved in the pedagogical approach. The word "experiential" essentially means that learning and development are achieved through personally determined experience and involvement, rather than on received teaching or training, typically in group, by observation, listening, study of theory or hypothesis, or some other transfer of skill or knowledge. We might also regard experiential learning as growing a person from the inside, whereas conventional teaching and training is the transfer of capability into a person from the outside [1, 2]. Developing people as individuals, which is at the heart of experiential learning, implicitly enables learning methods to fit each person's own preferred learning styles and natural preferences, because learners are encouraged and helped to learn and develop in their own ways, using methods which they find most comfortable and therefore enjoyable, such as ICT tools. The latter helped us identify an experience in which students will find interest and be personally committed; the learning experience was approached in a positive, non-dominating way.

This type of individual-based learning on which all HIPON case presentations have been established, includes the following elements:

- Reflection, critical analysis and synthesis. HIPON developers took into account that a learning activity is a process that is a means to an end, not an end in itself. Critical thinking is therefore enhanced through the sequential apposition of carefully selected diagnostic microscopic images starting from low magnifications which permit the lesions' general patterns recognition and passing to higher magnifications which highlight specific valuable histological features. Learning from the process is at the heart of experiential learning.

- Opportunities for students to take initiative, make decisions, and be accountable for the results. During the diagnostic procedure, HIPON users are asked to decide whether they need further information to make their diagnosis and, if so, critically select the kind of information that is indeed necessary among various histochemical or immunohistochemical stains, some of which are irrelevant, and among patients' history, imaging and other clinic-laboratory data. Mistakes are actually opportunities for learning. It's obvious that if something in the diagnostic procedure goes wrong, there will be benefit in review and change. This possibility is offered to HIPON platform users who can go back and retry the diagnostic test. At the end of each case, the correct as well as the wrong alternative diagnoses are deftly analyzed.

- Opportunities for students to engage intellectually, creatively, emotionally, socially, or physically. HIPON users have the possibility to communicate with their peers, sharing their reactions and observations, by making use of the HIPON "Histo-book", in accordance with social media practices.

- A designed learning experience through HIPON cases that includes the possibility to learn from natural consequences, mistakes, and successes. In this way, it is more likely to produce positive emotional effects, notably confidence, self-esteem, and a sense of personal value and purpose. 


\section{Emergence of Medical Teacher's Roles Through HIPON}

Teaching is an activity which is helping the student in learning. Teaching and learning are being modified due to innovations in education. Teachers have to understand the modern trends in teaching-learning process and make learning more interesting and interactive, so that students may learn better. By implementing experiential learning, there is a move to a more student-centered view of learning which has required a fundamental shift in the role of the medical teacher. No longer is the teacher seen predominantly as a provider of information, but rather as a facilitator or manager of the student's learning. Students must take control of their own learning. In the experiential learning procedure, the "instructor" is a guide, a cheerleader, a resource, and a support. Suitable experiences are carefully chosen for their learning potential by the teacher who commences the experience and guides students through the process of finding and determining solutions for themselves $[3,4]$. The introduction of experiential learning based on real cases, as presented in HIPON, is directly related to this fundamental change in the student-teacher relationship. In HIPON case presentations practical teachers share with the user their thoughts as reflective practitioners, helping to illuminate, for the student, the process of clinic-pathologic diagnosis making. In this regard, an educator's most important responsibility is to search out and construct meaningful educational experiences that allow students to solve real-world problems; the result is that any abstract, inert knowledge that students used to memorize from dusty textbooks comes alive as they participate in the practical application of knowledge. Where one gets in touch with specific areas of knowledge from a teacher, one really learns how to implement that knowledge, how to live it, from a so called "mentor". Tuning in to how students really learn prompted HIPON educators to downgrade teaching that is primarily information- based in favor of instruction that challenges students to take an active role in learning through the interactive HIPON e platform and develop their abilities to think critically, solve problems and make informed judgments.

Traditional teacher's roles are also apparent in $\mathrm{HI}$ PON platform, at a secondary level, though:

- Information acquired through formal learning and past experience and always directly relevant to the practice of pathology is provided in the "overview" section of each Systemic Pathology HIPON chapter and remains to be skillfully applied to the "real world" setting of the cases' diagnosis section. After all, a teacher remains to some degree a person who at first imparts to the student a given body of information (in addition to skill and capability); then, of course, the teacher should provide the student with valuable opportunities to apply theory to practice.

- The role of teacher as resource material developer is evident in the selected references and web pages links of each HIPON chapter. Implementing an evidence-based approach to pathology learning and practice involves finding out about the latest research and propose it as studying material.

- The assessment of the user's competence is possible through the image-based stimulating tests at the end of each Systemic Pathology chapter.

\section{Conclusion}

The most complete answer to the question: "Why should one teach?" is simple and concise: "Teach to make a difference". How, where and to whom one makes a difference is up to him/her. As far as we are concerned, we have frankly attempted to make a difference in pathology teaching through HIPON e platform in which students decide themselves to be personally involved in the learning, practical problem-solving experience. Students learn through student- rather than instructor-centered experien- 
ces by doing, discovering, reflecting and applying. Through these simulating experiences students develop communication skills and self-confidence and gain and strengthen decision making skills by responding to and solving real world problems and processes. Thereby, when they next find themselves in an environment that presents a challenge like the challenge presented in the simulation, they will more readily recall that experience and the things that they have learned from it.

\section{Acknowledgement}

All authors express their gratitude to the staff of AVMap Group of Companies for their administrative support.

\section{References}

1. Donna M. Qualters: Bringing the outside in: Assessing experiential education. New Directions for Teaching and Learning. Special Issue: Experiential Education: Making the Most of Learning Outside the ClassroomVolume 2010, Issue 124, pages 55-62, Winter 2010.

2. Alan Ewert and Jim Sibthorp: Creating Outcomes Through Experiential Education: The Challenge of Confounding Variables. Journal of Experiential Education - 2009, Volume 31, No.3 pp. 376-389

3. Susan A. Ambrose, Michael W. Bridges, Michele DiPietro, Marsha C. Lovett, Marie K. Norman, Richard E. Mayer (Foreword by): How Learning Works: Seven Research-Based Principles for Smart Teaching ISBN: 978-0-470-48410-4,336 pages, May 2010, Jossey-Bass.

4. Randy Bass: Disrupting Ourselves: The Problem of Learning in Higher Education (EDUCAUSE Review) Published on Wednesday, March 21, 2012.

\section{Comment on this article:}

\section{(f) (B) in $8+S$}

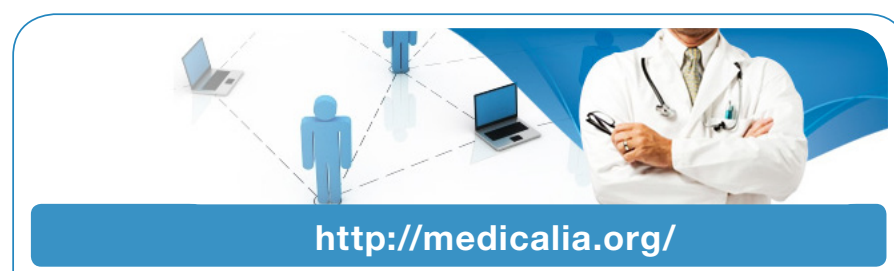

Where Doctors exchange clinical experiences, review their cases and share clinical knowledge. You can also access lots of medical publications for free. Join Now!

\section{Publish with iMedPub}

http://www.imed.pub

International Archives of Medicine is an open access journal publishing articles encompassing all aspects of medical science and clinical practice. IAM is considered a megajournal with independent sections on all areas of medicine. IAM is a really international journal with authors and board members from all around the world. The journal is widely indexed and classified Q1 in category Medicine. 